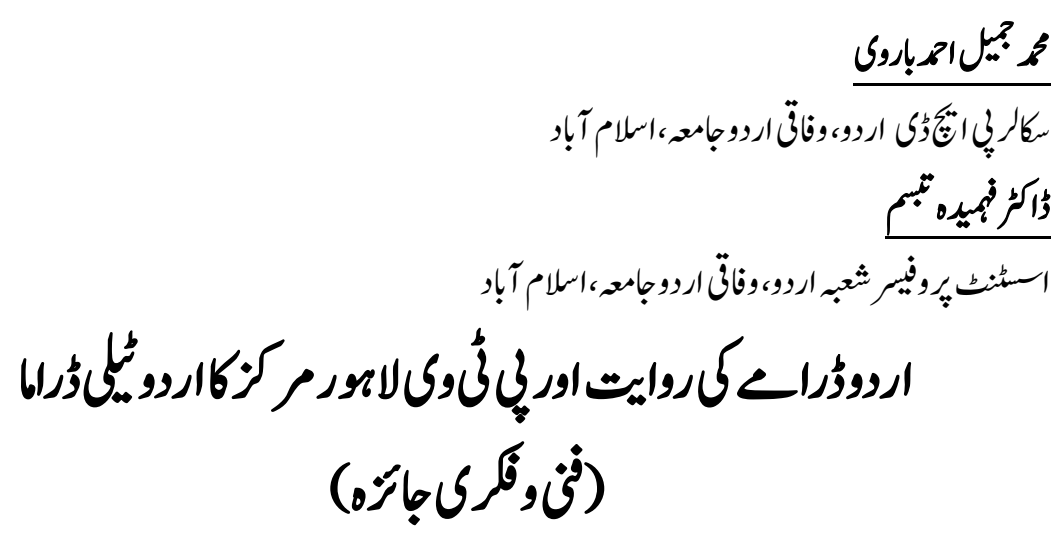

Muhammad Jamil Ahmad Barvi

Scholar PhD Urdu, Federal Urdu University, Islamabad Dr. Fehmida Tabassum

Assistant Professor, Department of Urdu, Federal Urdu University, Islamabad

\title{
Tradition of Urdu Drama and Tele Drama of PTV Center Lahore: A thought Provoking and Artistic Review
}

Drama has always been so powerful medium taht it had permeated every form of communication. Although with the passage of time and growth of civilization new form of narratives expression.e.g prose, essay, fiction, poetry etc emerged but could not surpass the supermacy of drama and dialogue.It was this power of the dramd which made it JJpart of psalms and scriptures. Lahore being thJe heart of Pakistan, presents a strong cultural and social influence, PTV Lahore center is honoured to present the very true picture of country's cultured hub. Urdu drama remains the hall mark of PTV Lahore center and has been the champion due to its quality production coupled with the depth of script and the level of direction.

Key Words: Drama, Communication, Civilization, Culture, Production, Script, PTV Lahore. 


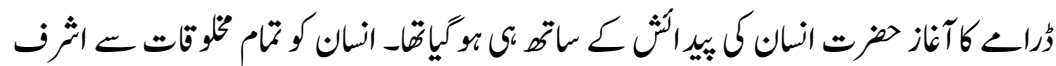

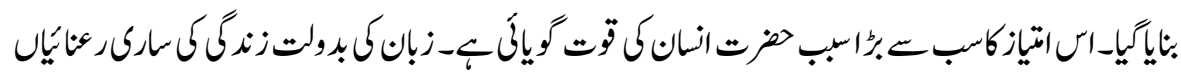

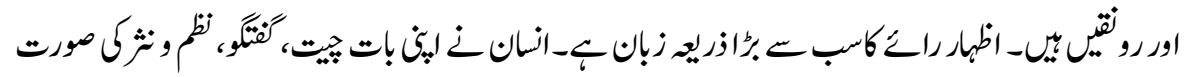

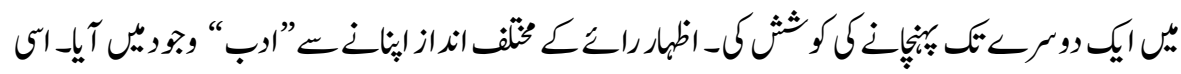

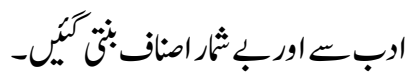

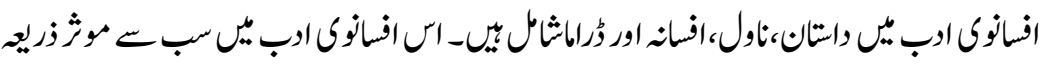

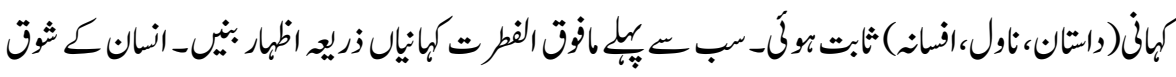

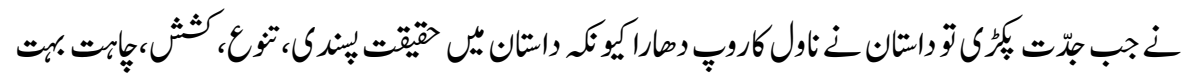

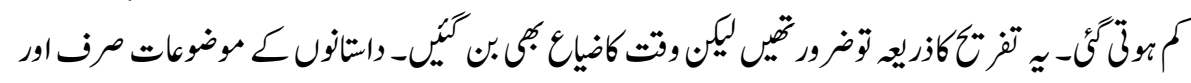

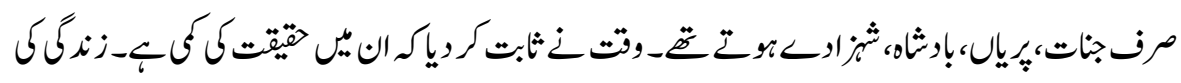

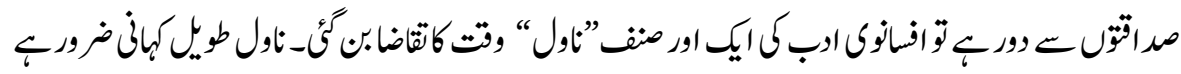

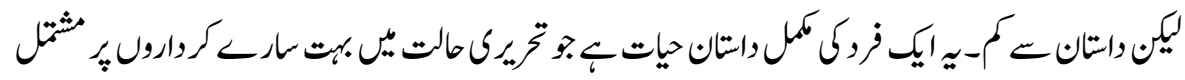

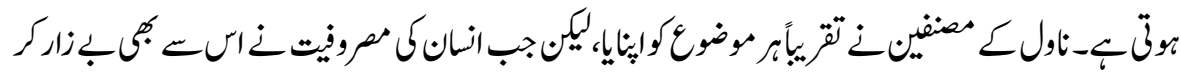

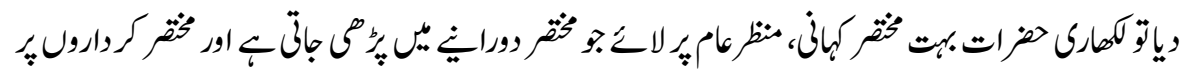

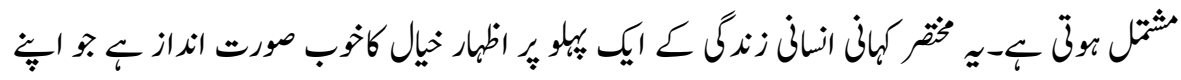

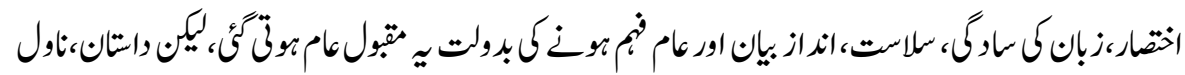

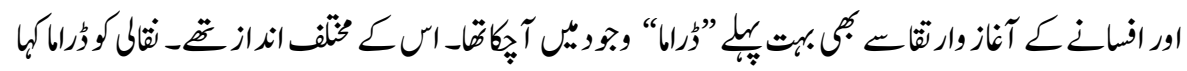

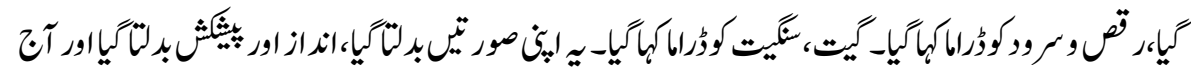

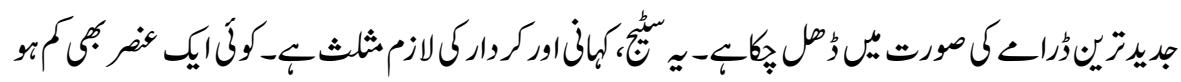

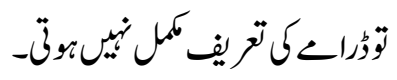

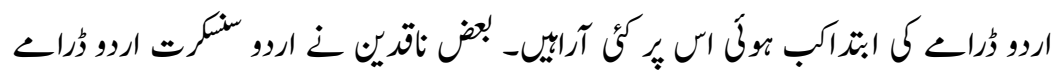

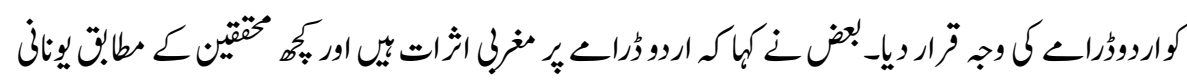

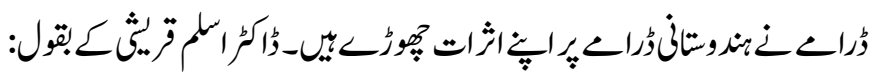




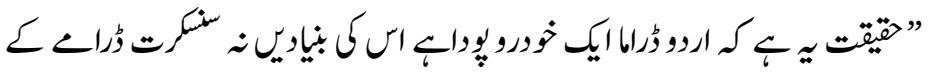

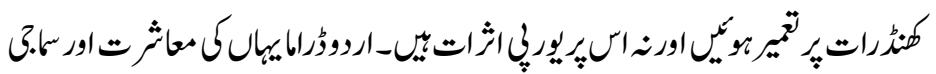

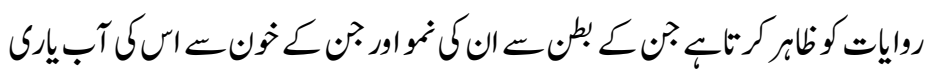

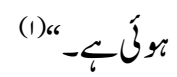

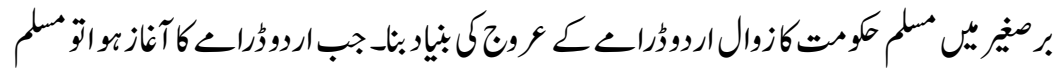

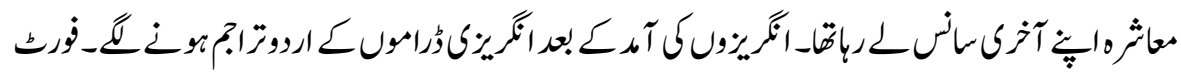

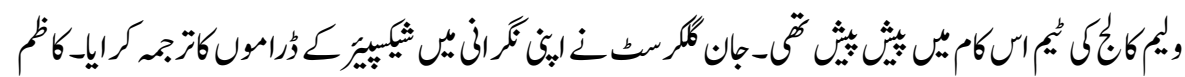

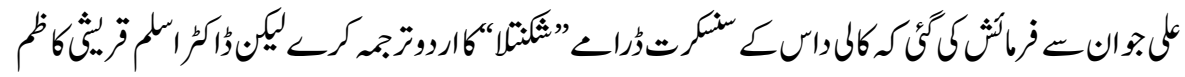

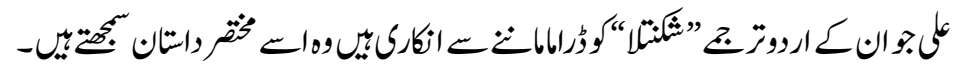

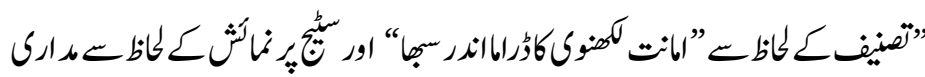

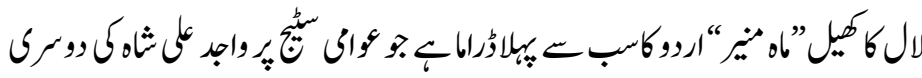

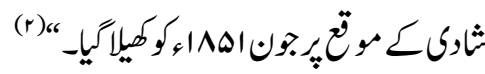

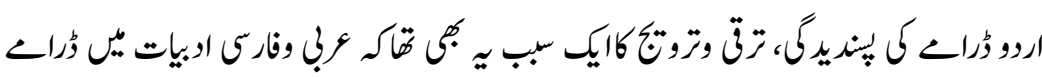

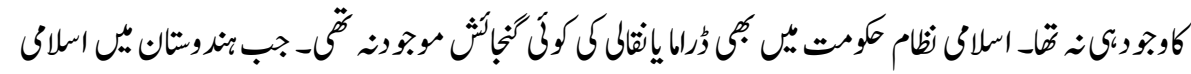

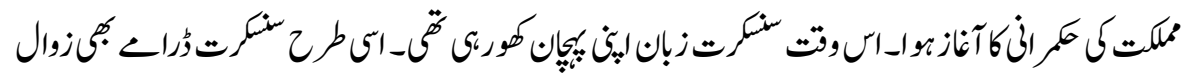

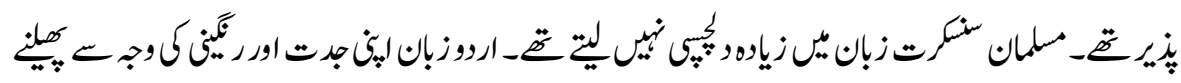

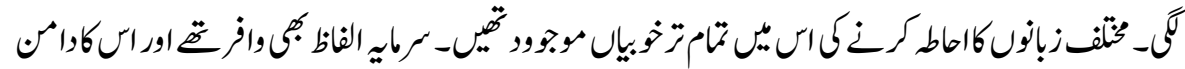

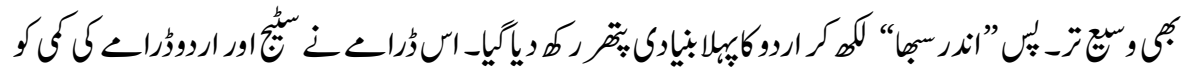

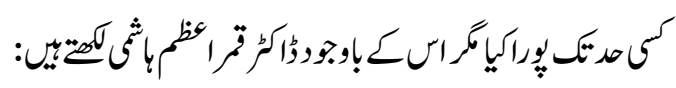

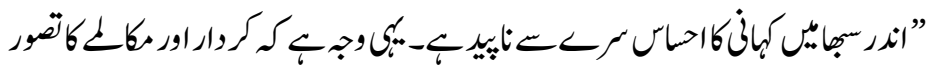

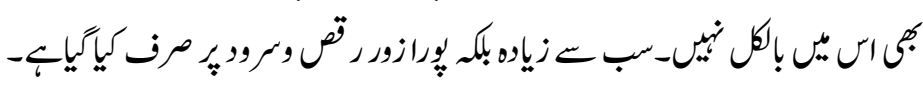

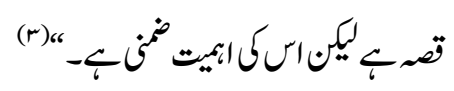




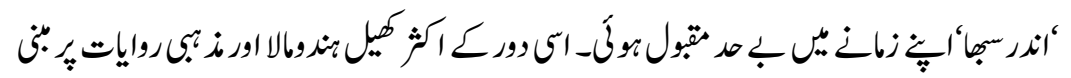

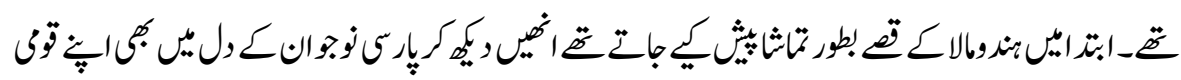

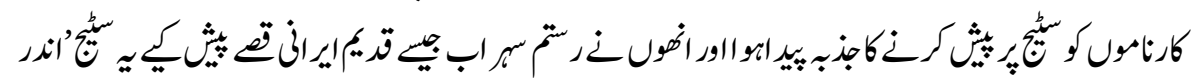

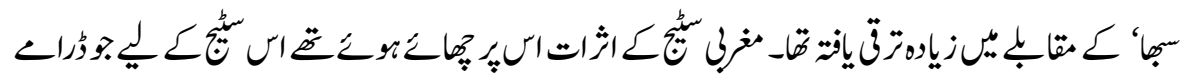

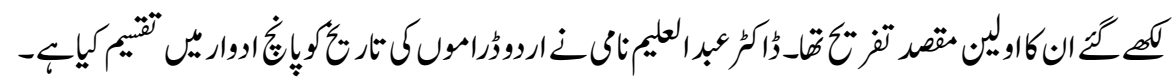

$$
\begin{aligned}
& \text { ציكلاور: } \\
& \text { ووّر اور: }
\end{aligned}
$$

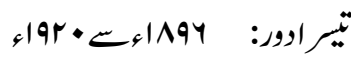

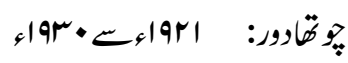

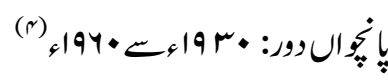

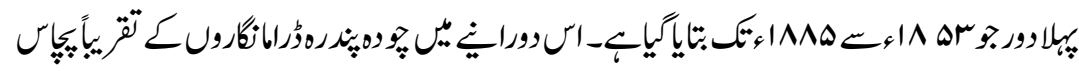

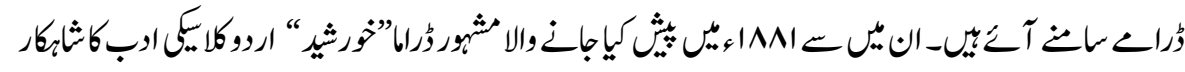

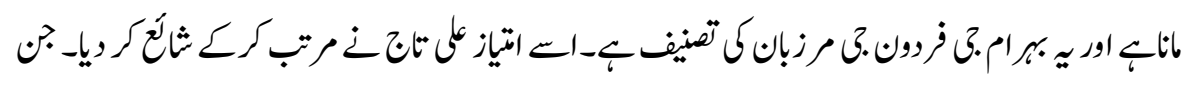

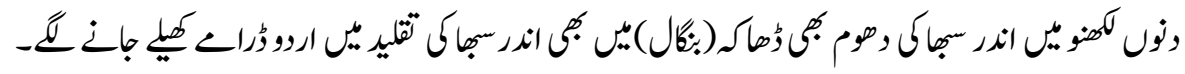

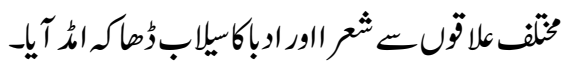

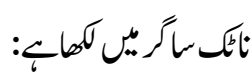

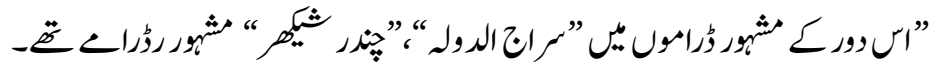

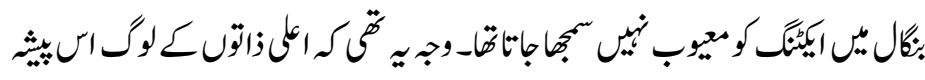

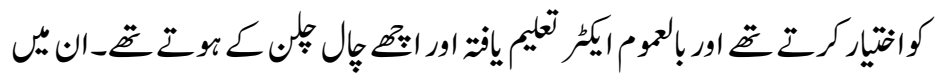

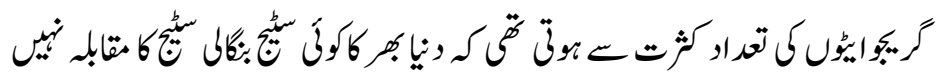

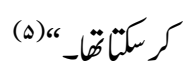

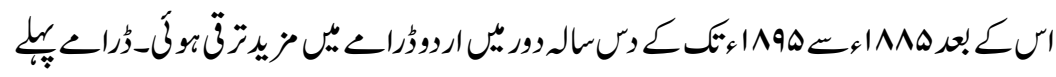

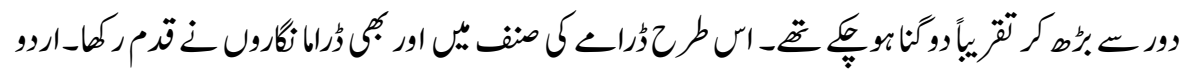




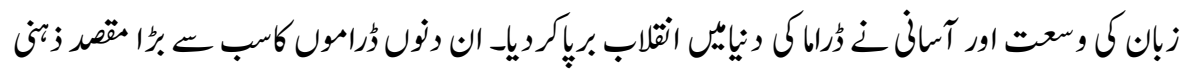

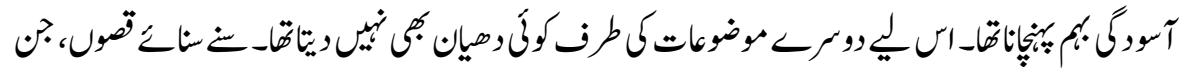

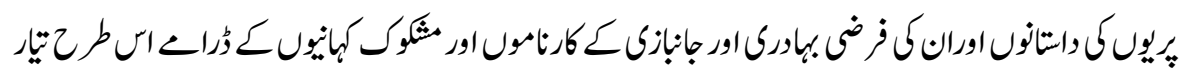

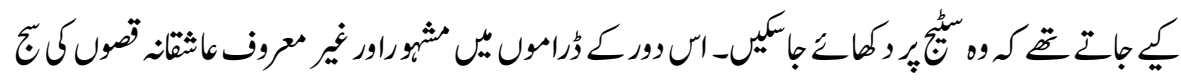

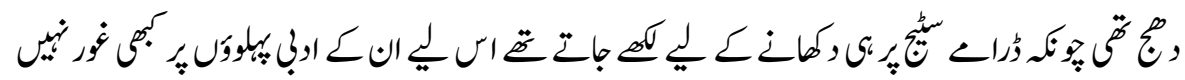

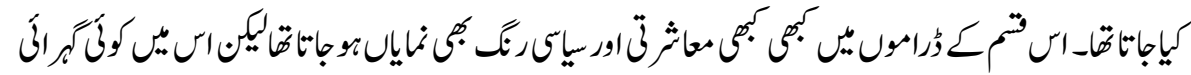

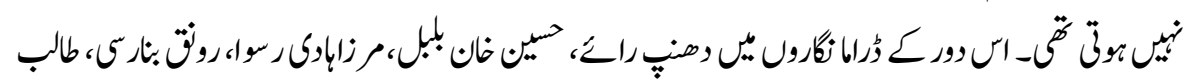

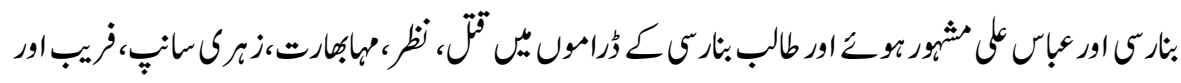

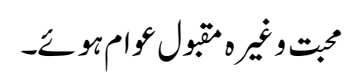

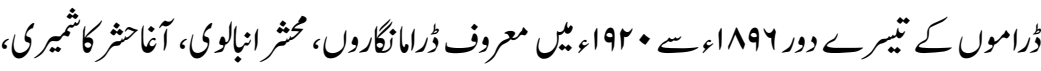

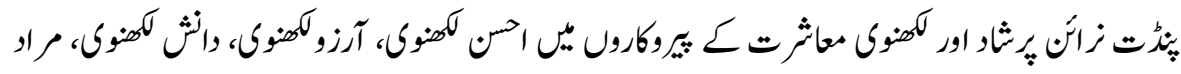

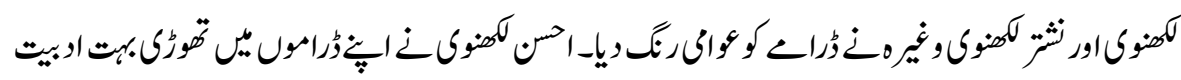

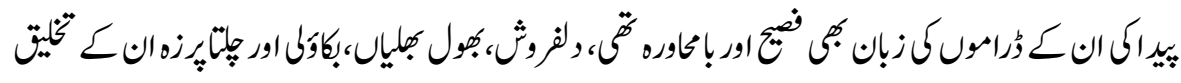
كروزراني

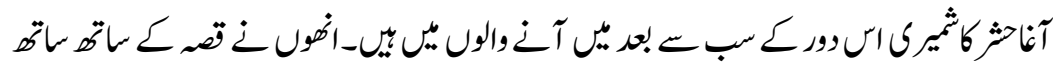

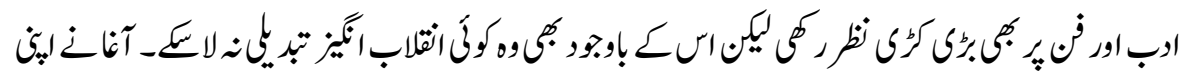

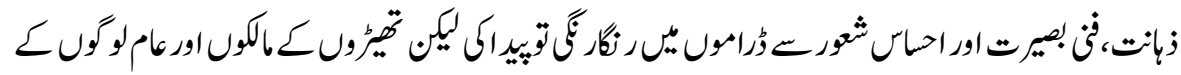

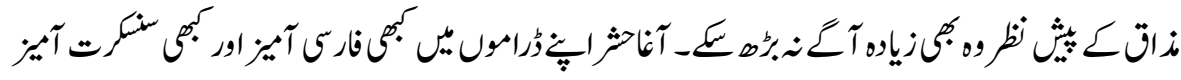

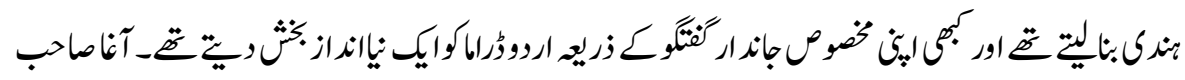

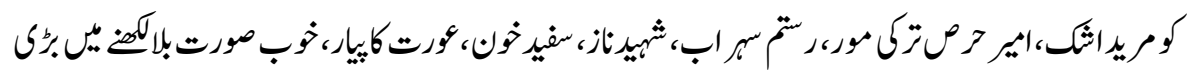
ثمت تلى 


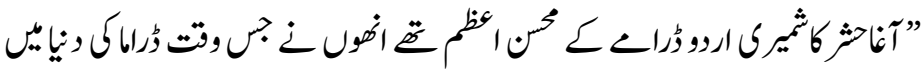

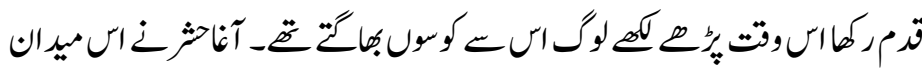

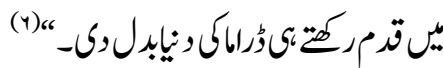

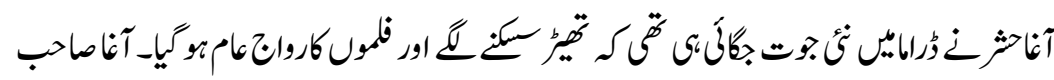

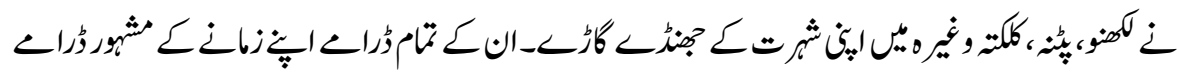

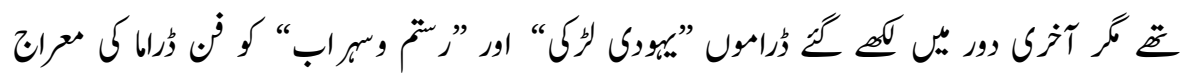

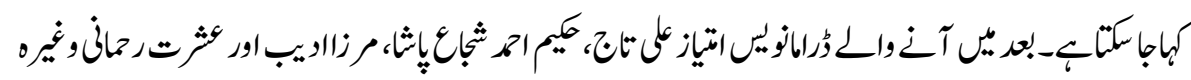

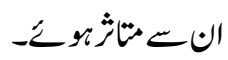

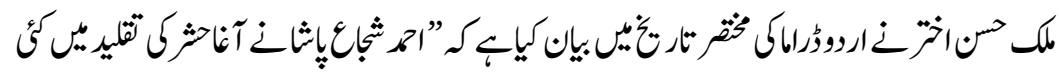

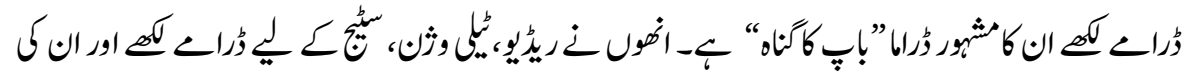

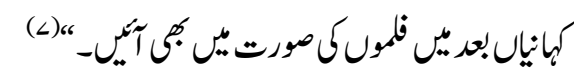

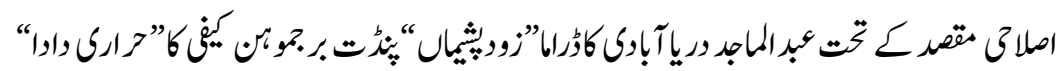

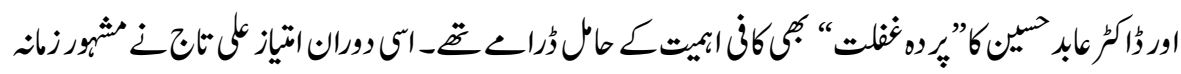

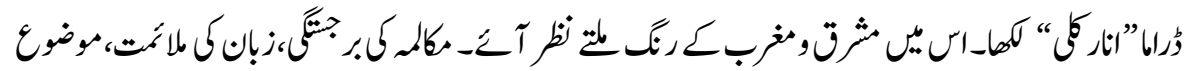

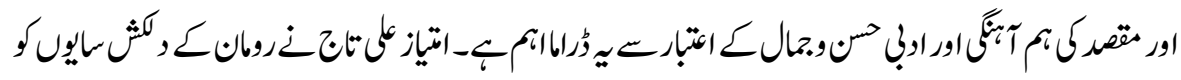

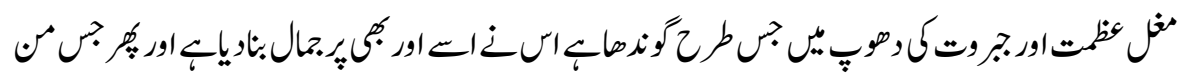

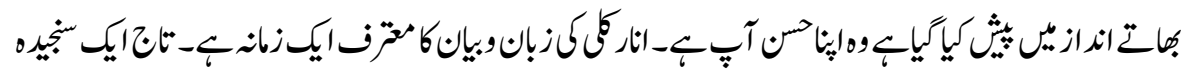

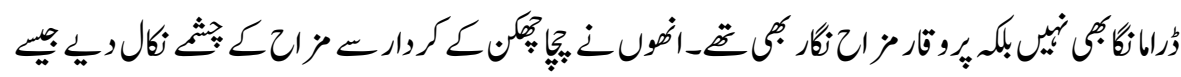

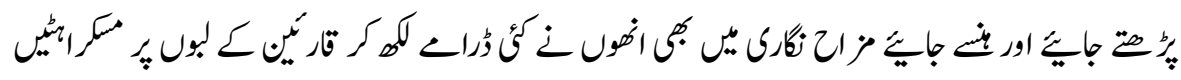

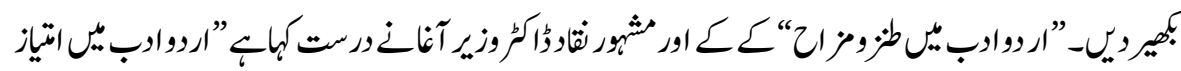

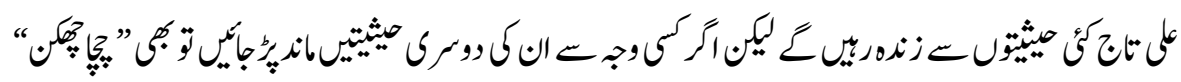

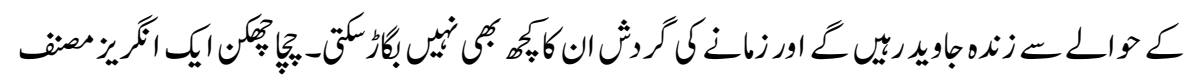




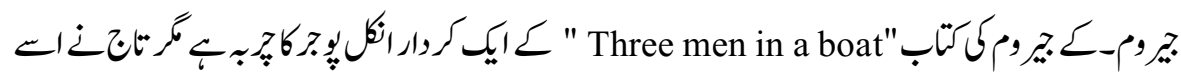

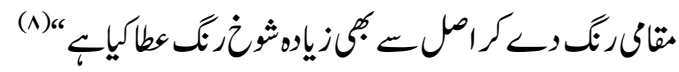

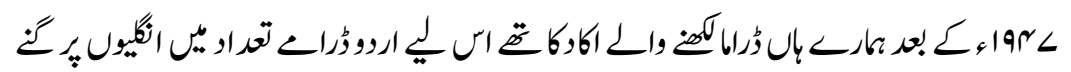

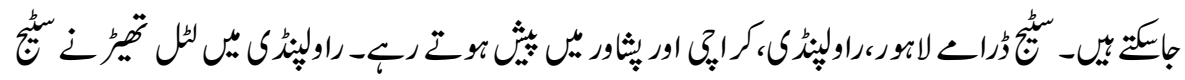

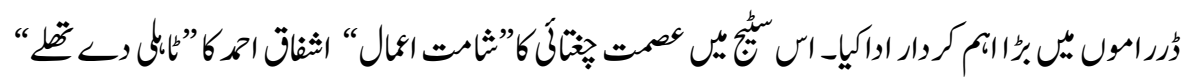

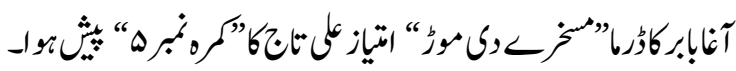

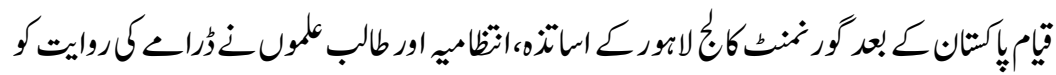

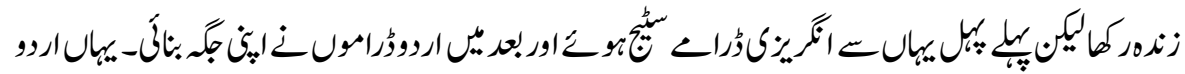

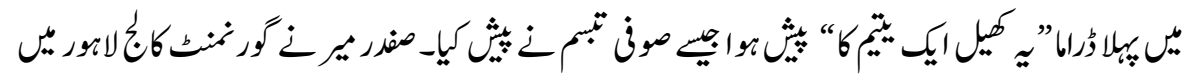

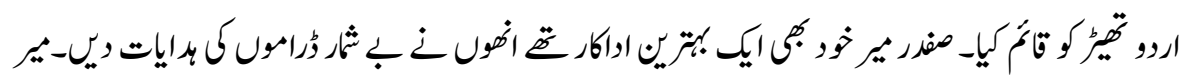

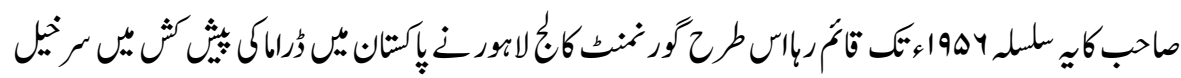
كاكرواركيا-

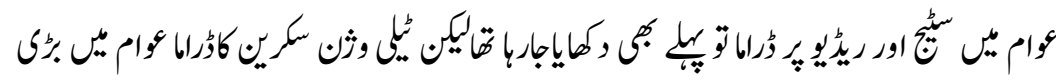

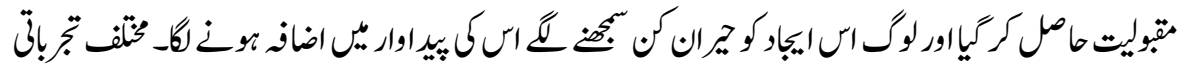

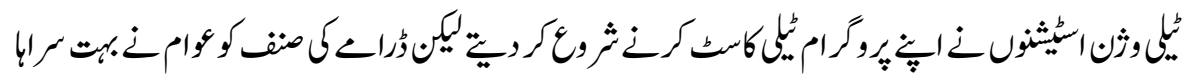

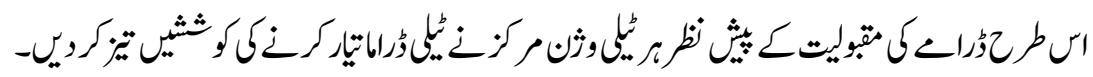

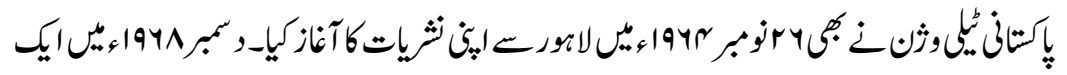

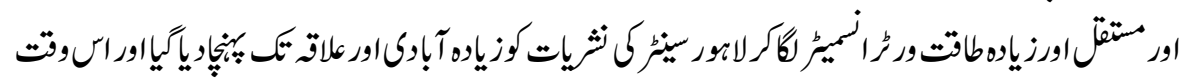

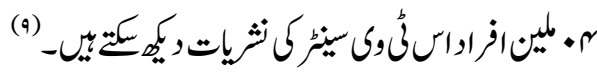

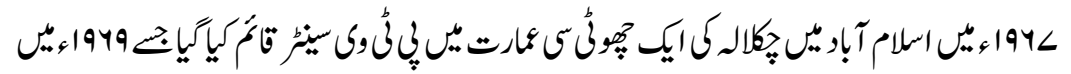

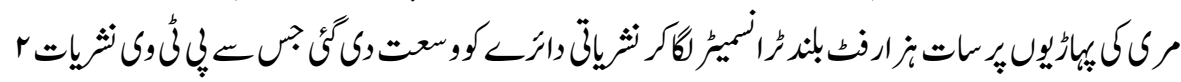

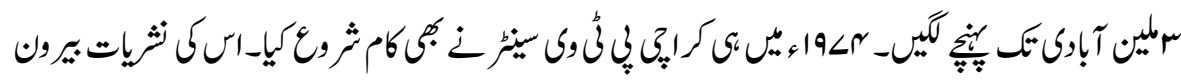

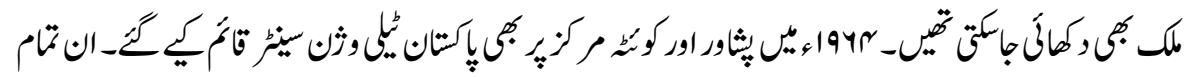




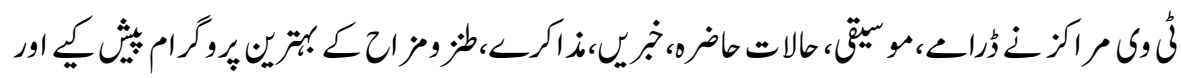

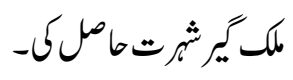

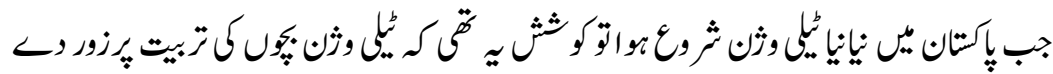

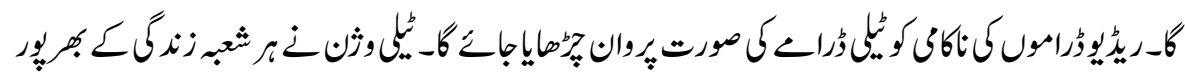

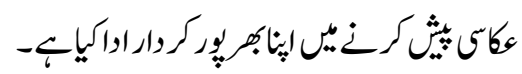

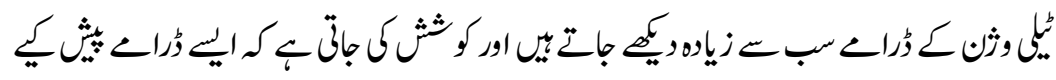

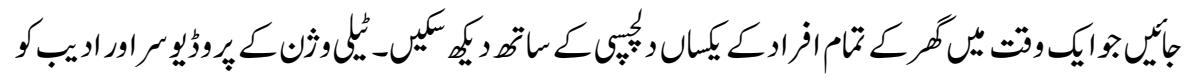

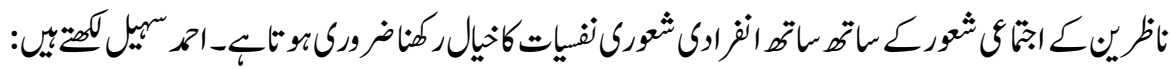

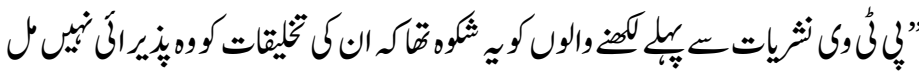

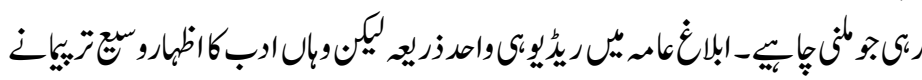

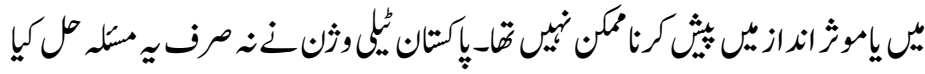

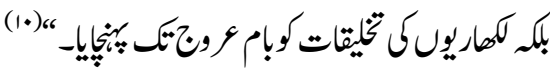

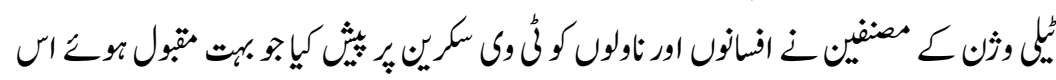

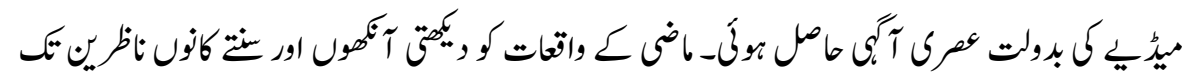

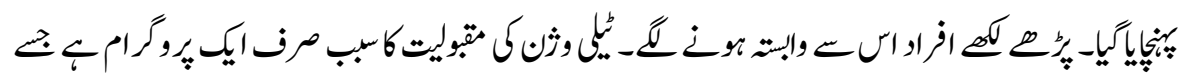

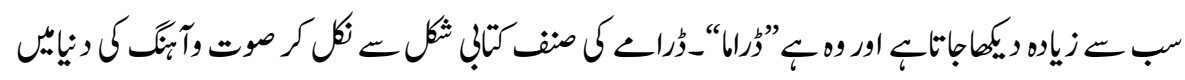

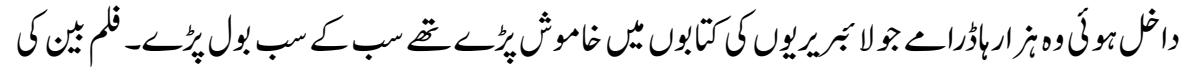

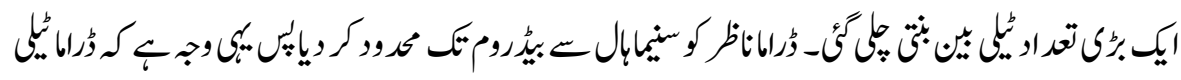

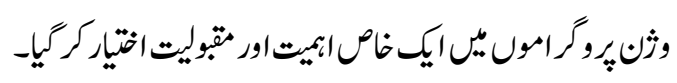

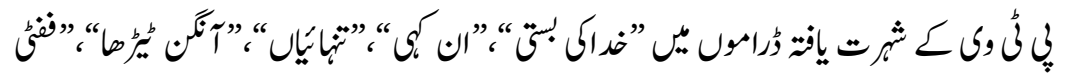

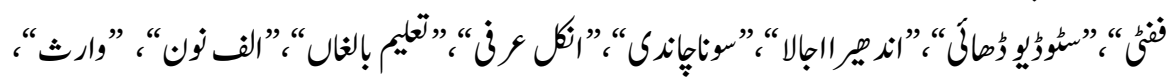

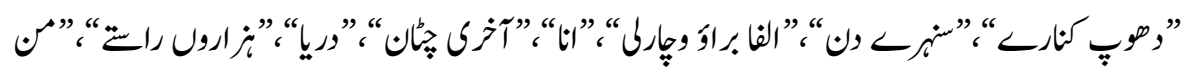
קِ 


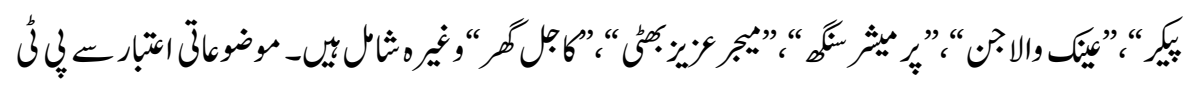

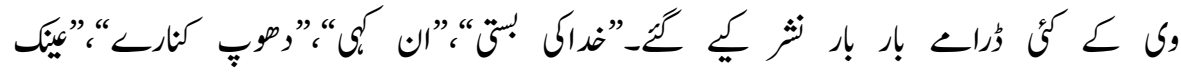

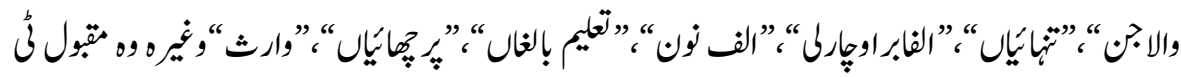

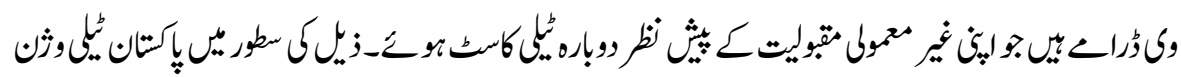

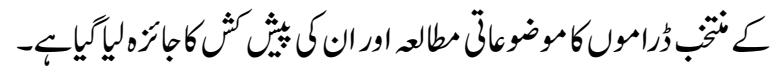

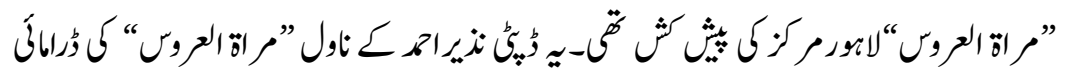

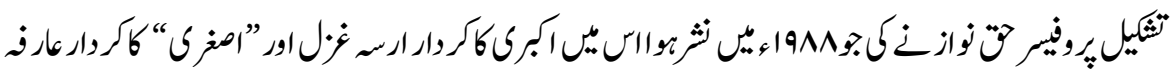

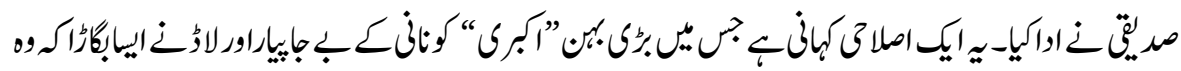

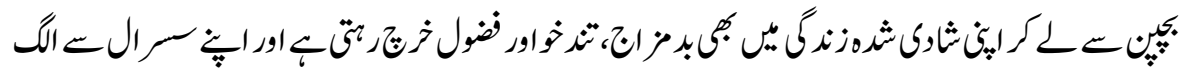

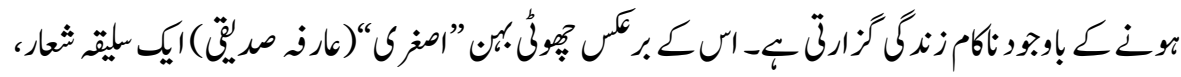

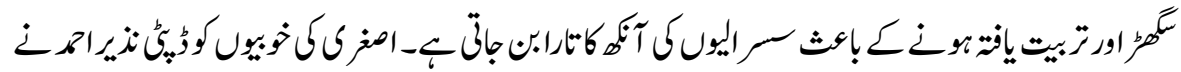
ثيكم ليولبيان كيا:

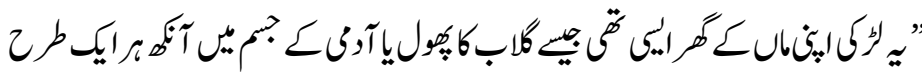

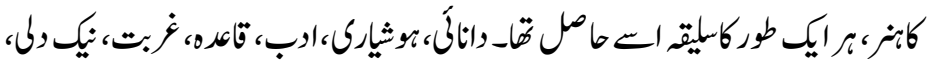

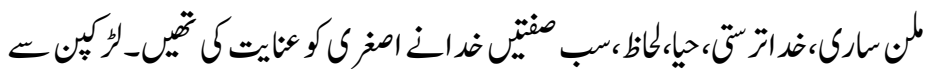

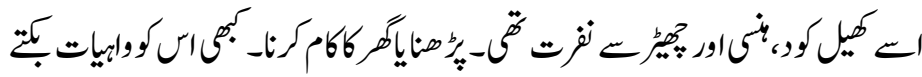

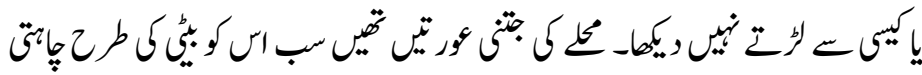

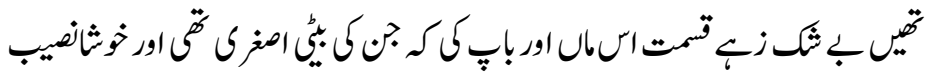

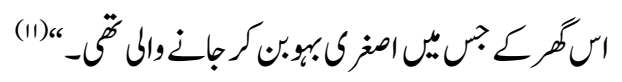

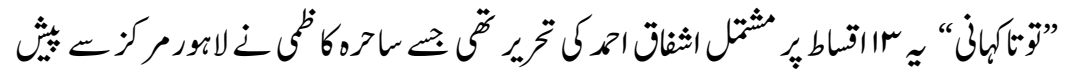

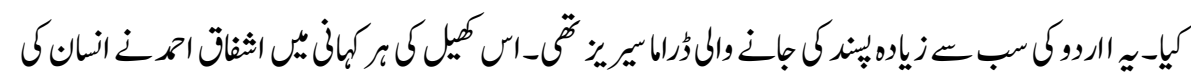

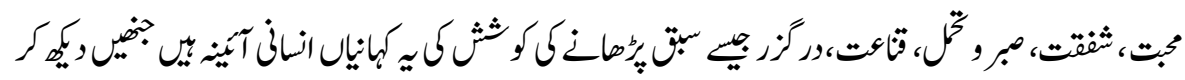




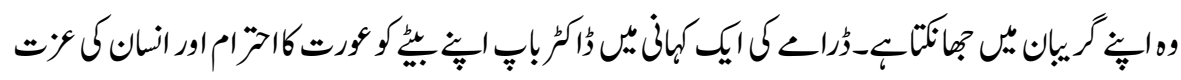

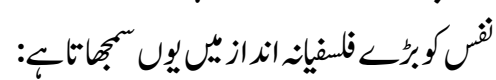

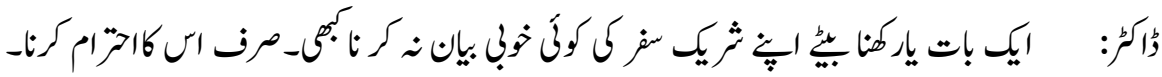

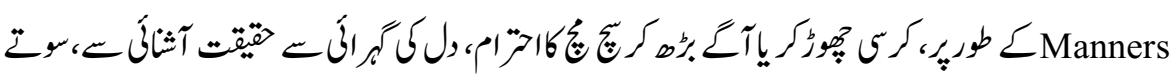
بإنقا象

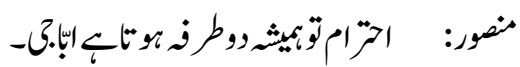

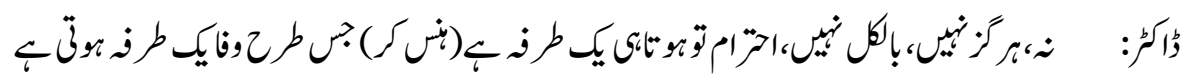

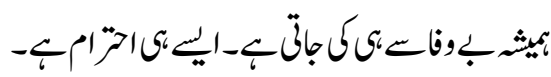

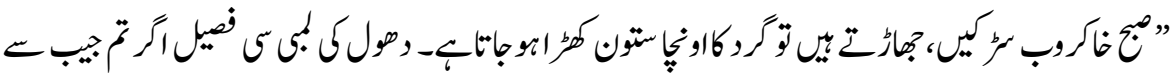

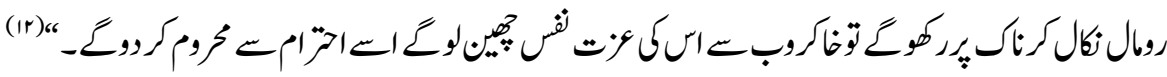

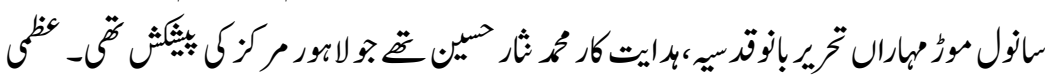

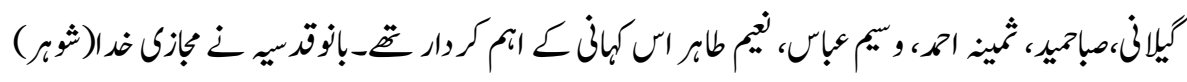

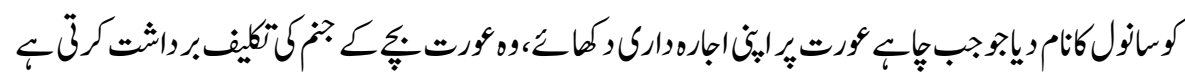

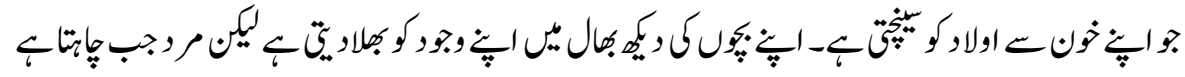

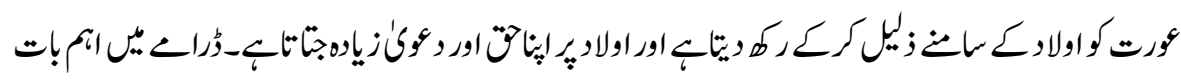

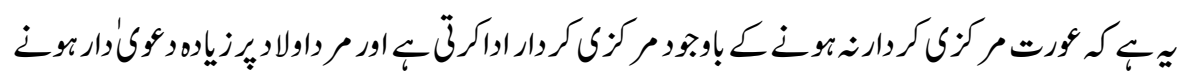

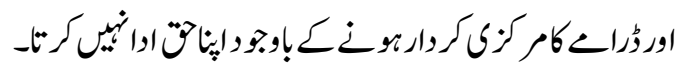

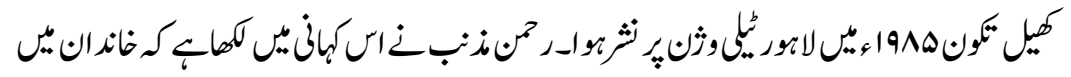

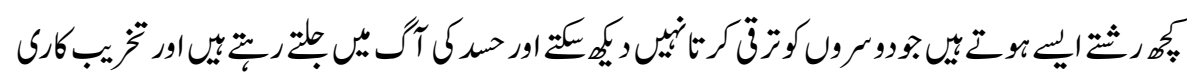

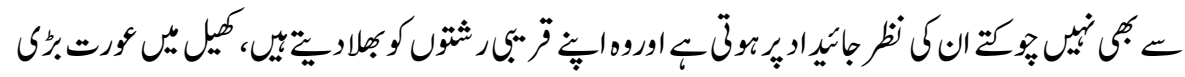

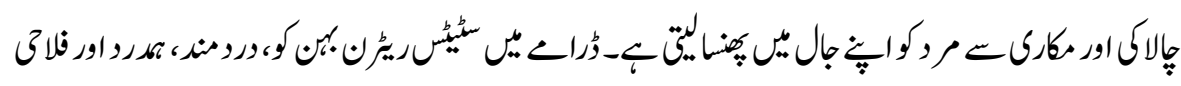

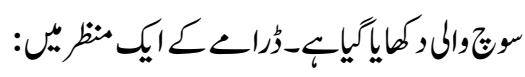

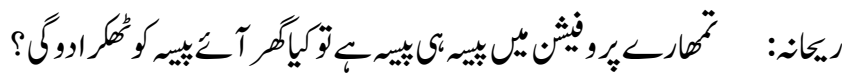




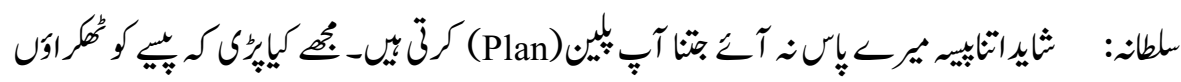

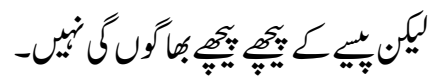

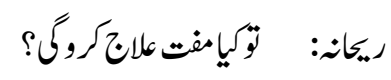

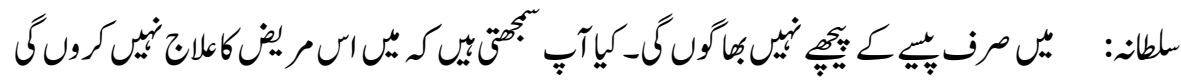

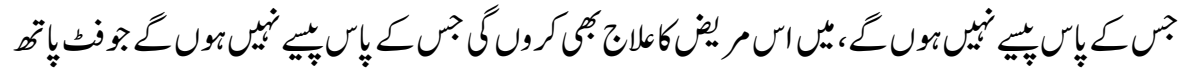

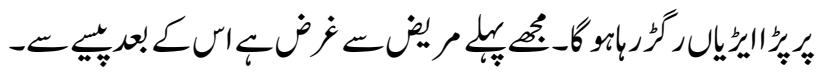
ريكان:

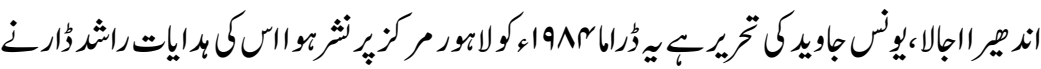

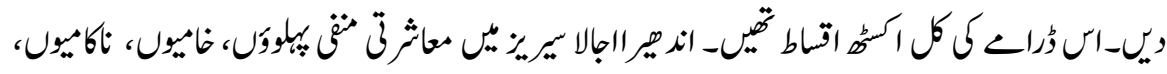

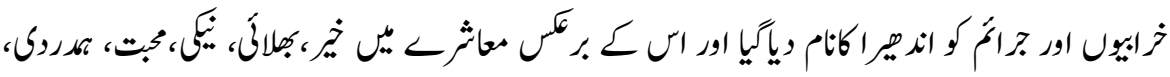

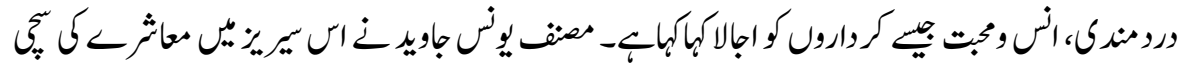

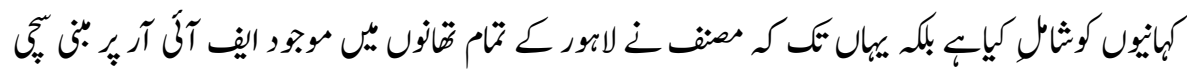

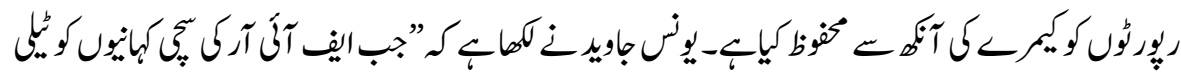

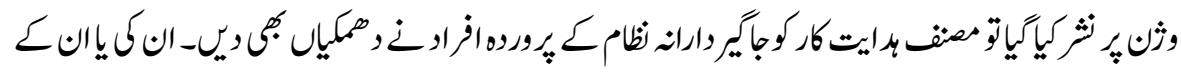

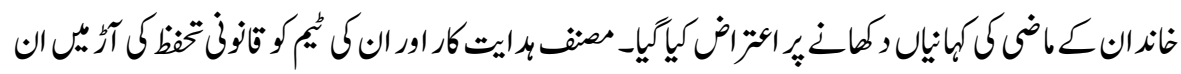
كبانيولكونثر كيآيا_، (ir)

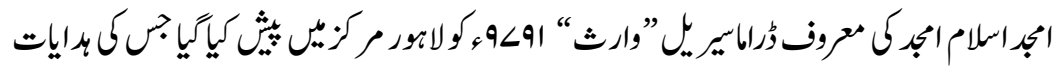

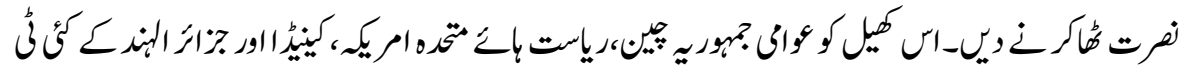

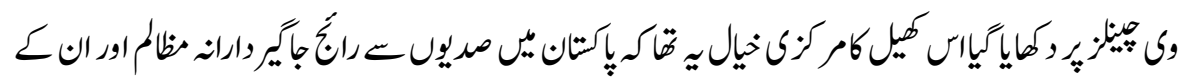

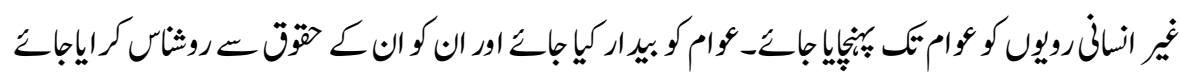

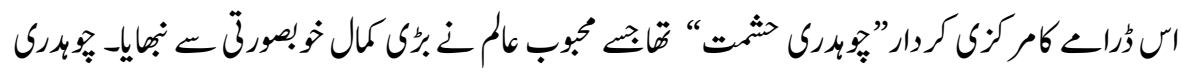

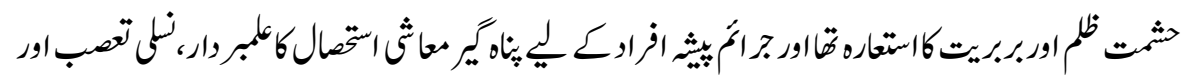




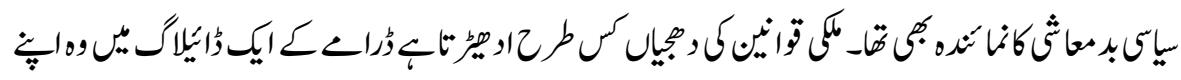

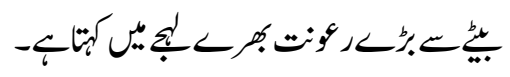

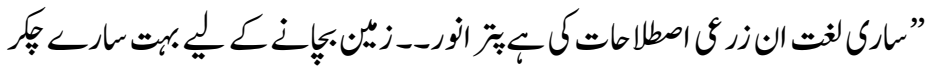

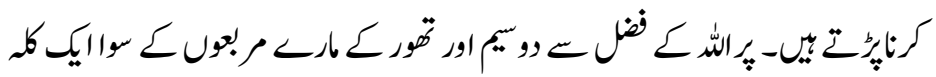

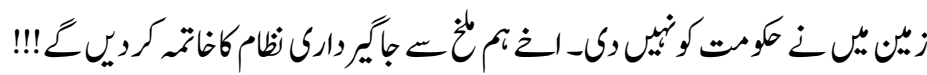

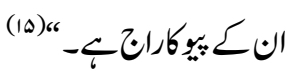

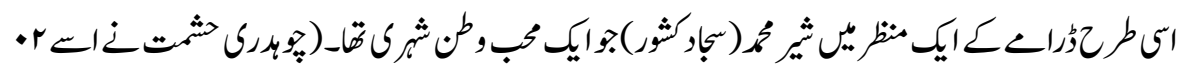

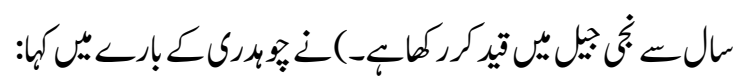

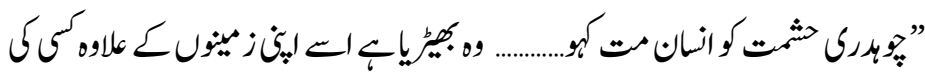

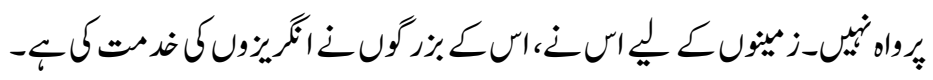

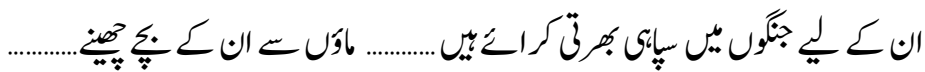

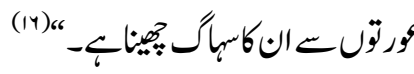

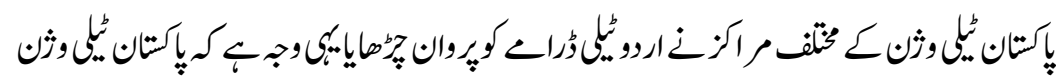

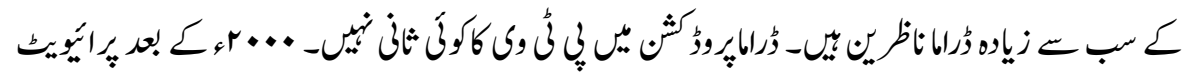

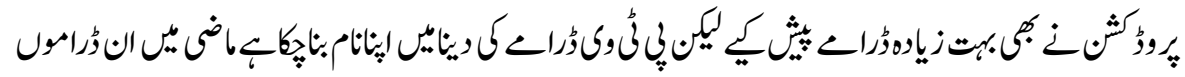

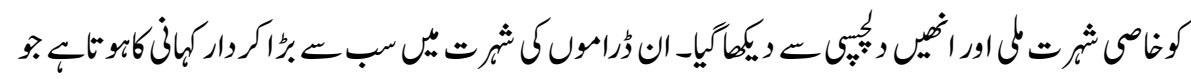

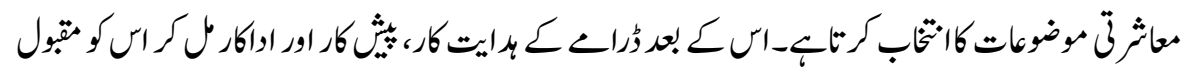

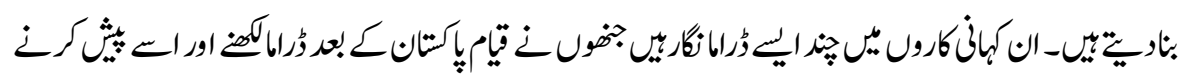

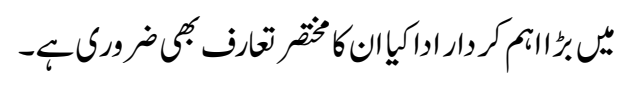

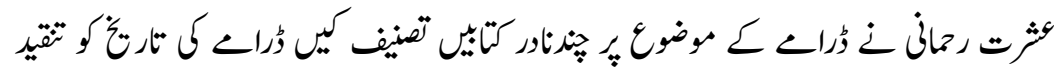

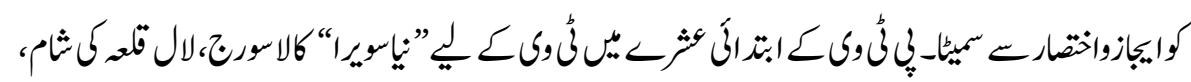

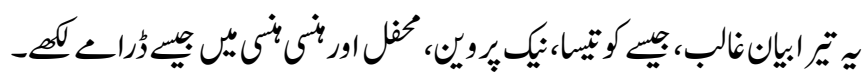




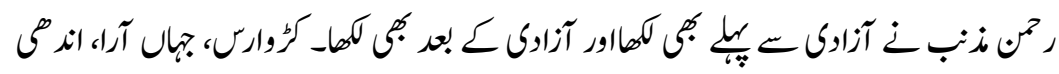

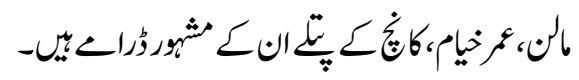

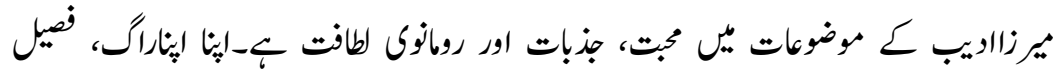

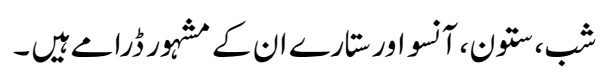

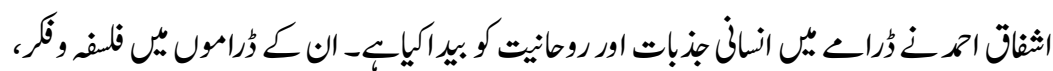

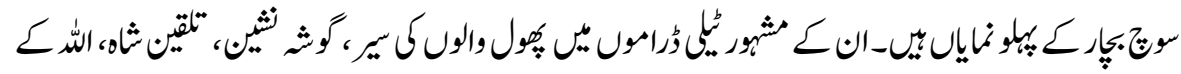

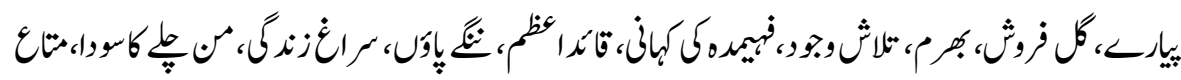

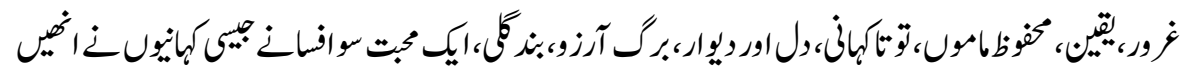

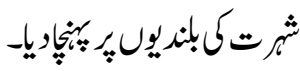

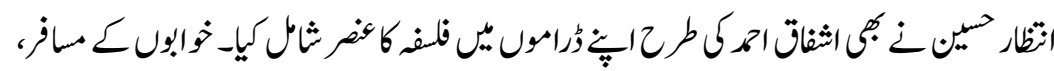

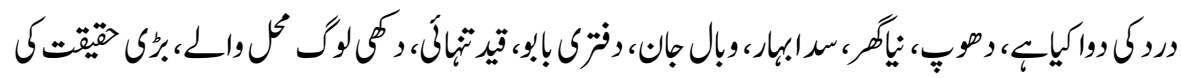

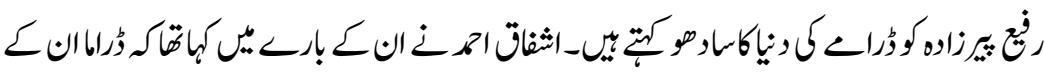

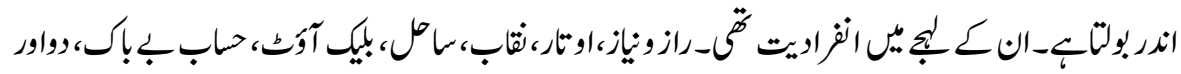

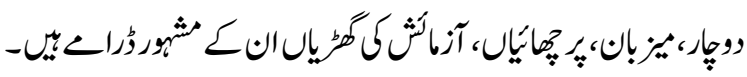

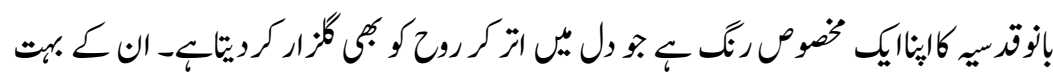

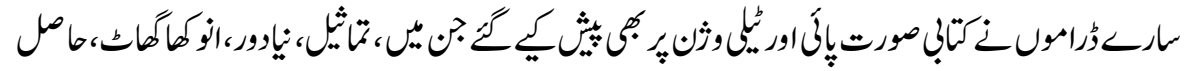

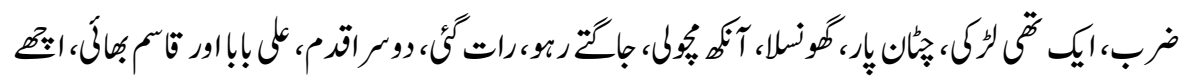

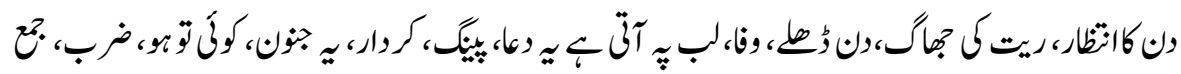

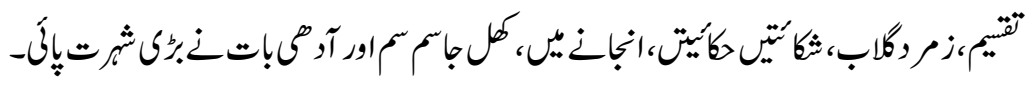

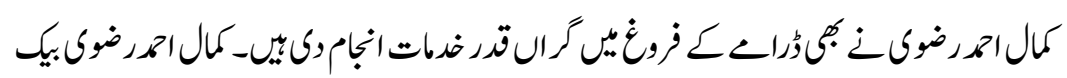

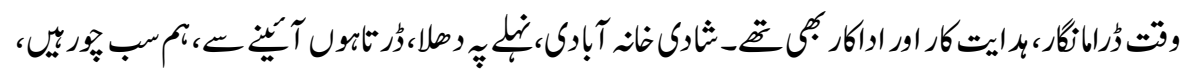

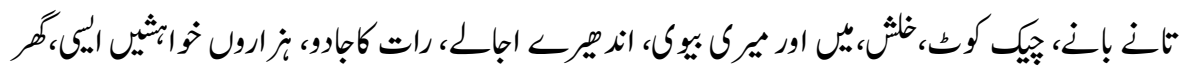




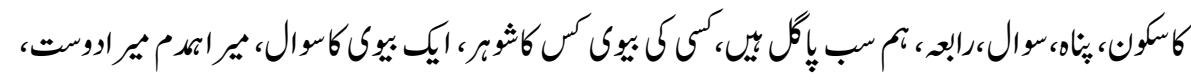

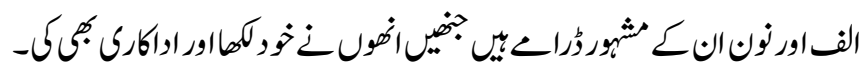

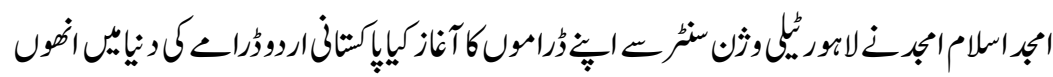

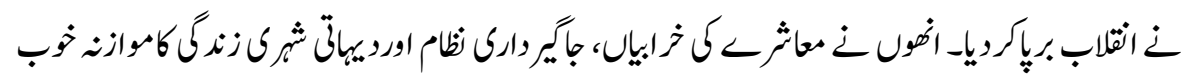

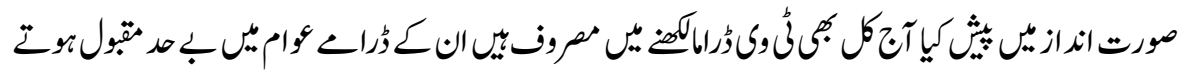

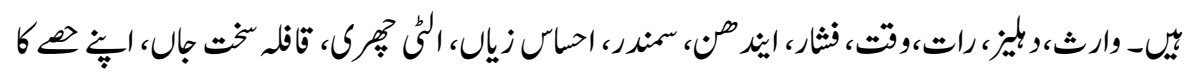

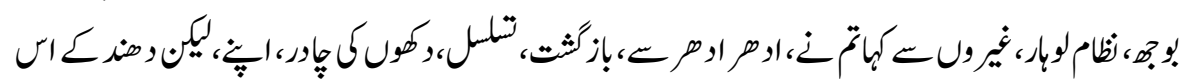

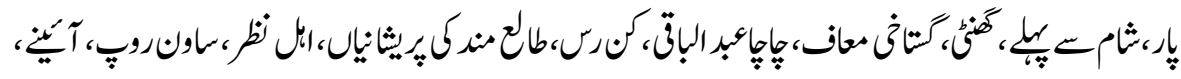

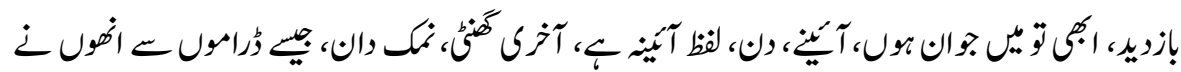

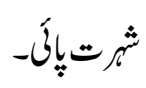

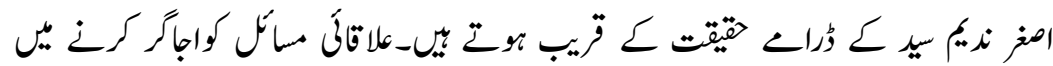

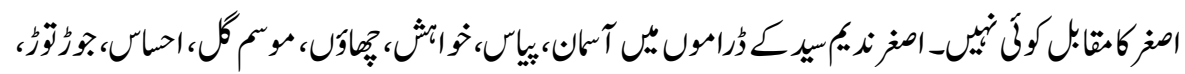

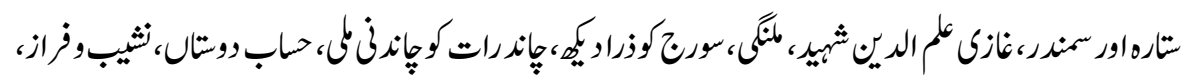

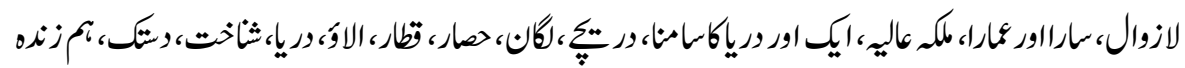

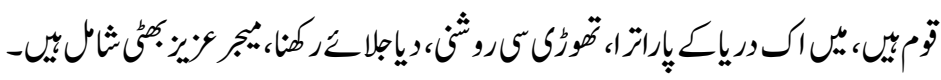

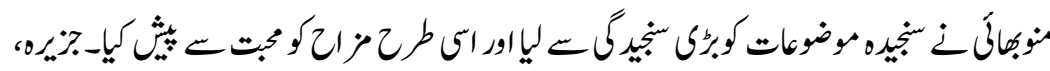

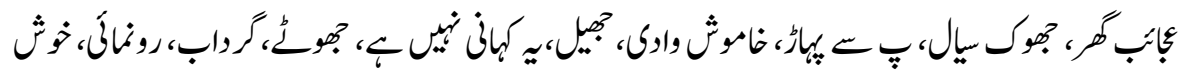

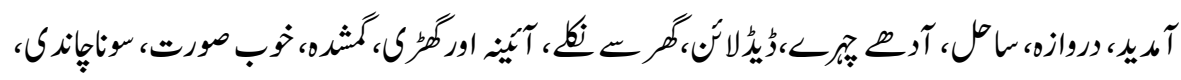

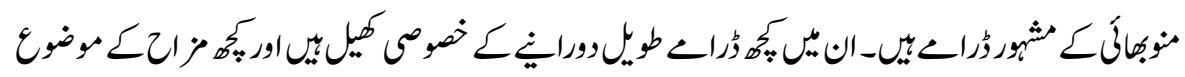

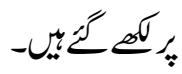

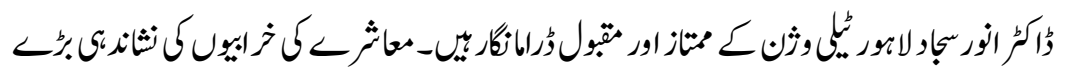

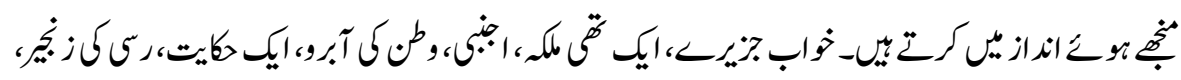

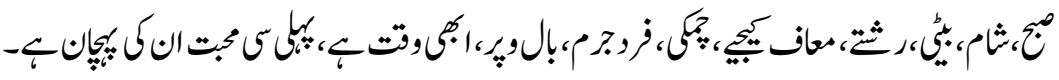




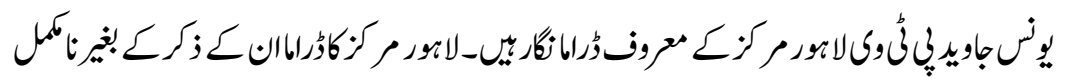

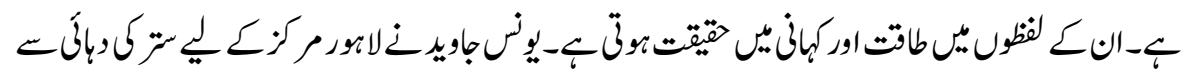

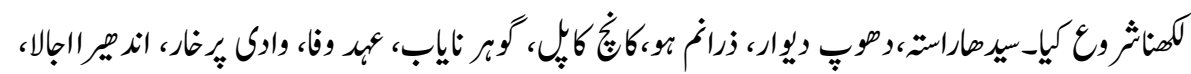

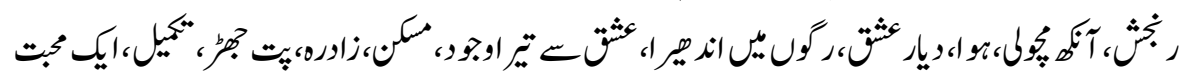

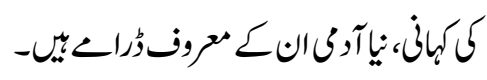

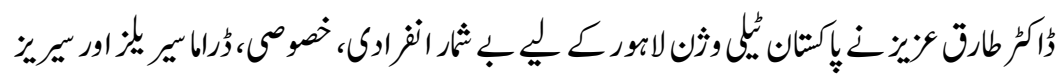

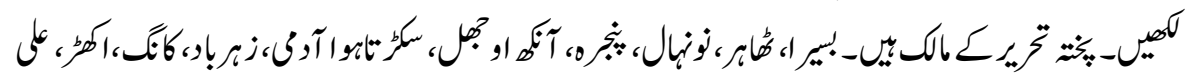

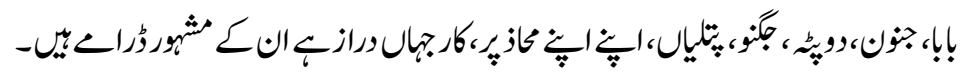

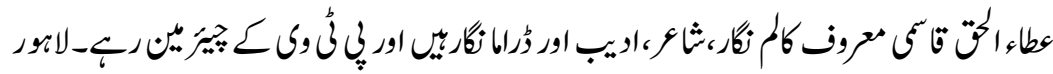

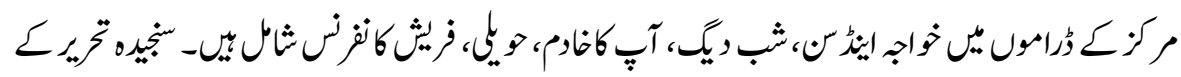
(1) (1)

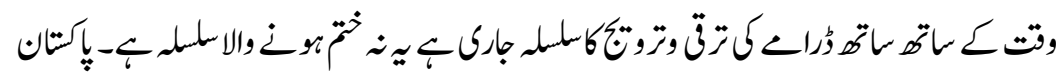

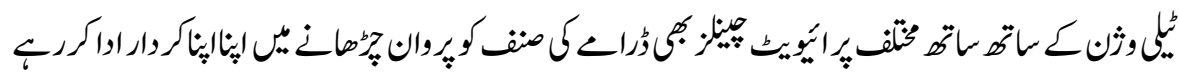

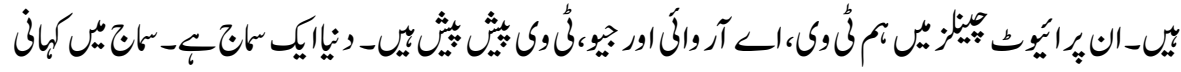

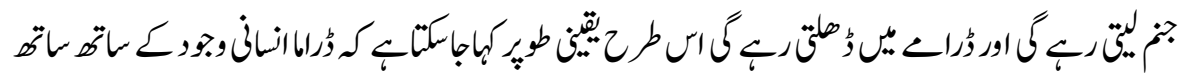

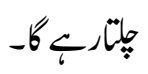

والرجات

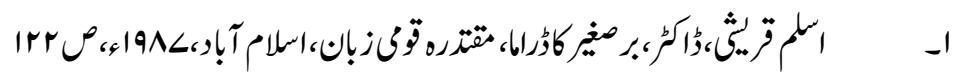

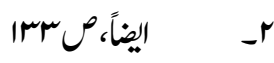

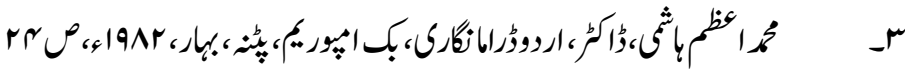

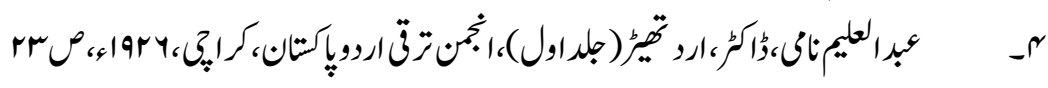

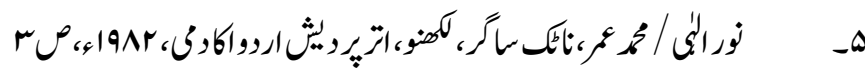

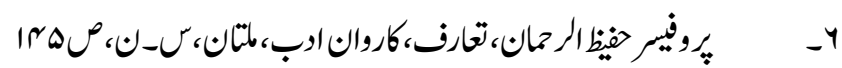




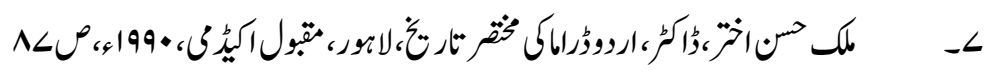

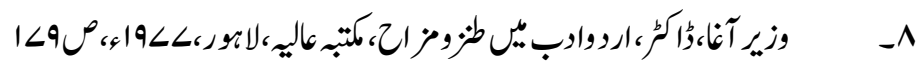

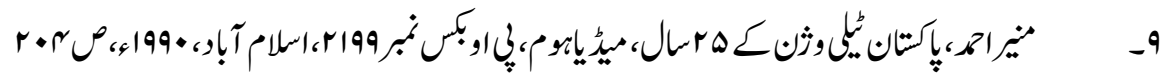

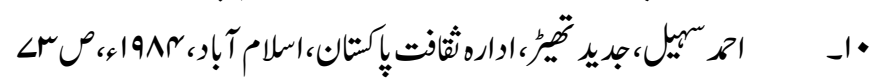

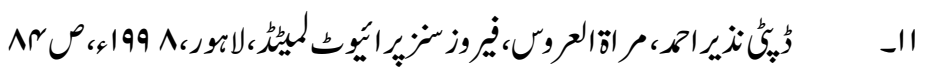

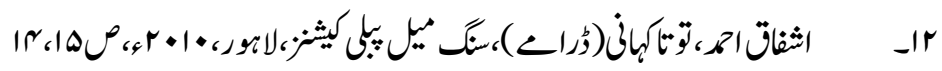

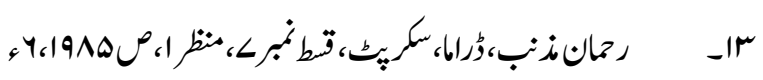

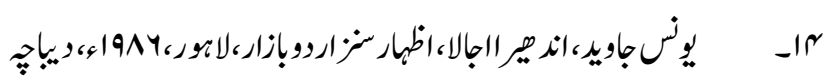

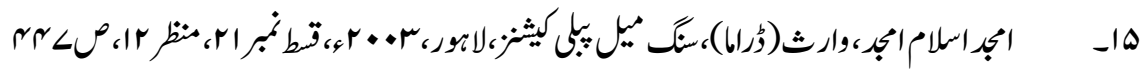

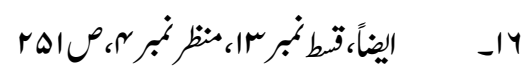

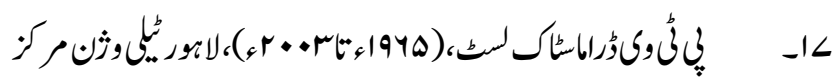

